\title{
KEMANDIRIAN SEKOLAH DALAM PENGELOLAAN KURIKULUM DAN PEMBELAJARAN DI MADRASAH TSANAWIYAH NEGERI LUWUK
}

\author{
Oleh : \\ Hasrat Aimang \\ hasratsambeabut@yahoo.com
}

\begin{abstract}
Abstrak
Penelitian ini di fokuskan bagaimana kemandirian dalam pengelolaan kurikulum dan pembelajaran di Madrasah Tsanawiyah Negeri Luwuk. Penelitian ini menggunakan deskriptif eksplanatori. Teknik pengumpulan datanya dilakukan secara kuntitatif dan kualitatif. Dari hasil sajian penelitian di lapangan ditemukan bahwa terdapat kemandirian dalam pengelolaan kurikulum dan pembelajaran karena Madrasah Tsanawiyah Negeri Luwuk dalam mempersiapankan seluruh perangkat baik dalam persiapan maupun dalam evaluasi pembelajaran.
\end{abstract}

Kata kunci : kemandirian, kurikulum, pembelajaran.

\section{PENDAHULUAN}

Desentralisasi merupakan kecenderungan yang sangat dominan di antara berbagai fenomena global. Adapun tuntutan dan kebutuhan desentralisasi pendidikan muncul dan berkembang sebagai bagian dari agenda besar-global tentang demokratisasi dan desentralisasi pemerintahan dalam rangka mewujudkan tata pemerintahan yang baik (good governace). Sebagai salah satu isu strategis dengan desentralisasi pendidikan diusahakan pemerintah mampu memberikan pelayanan pendidikan kepada masyarakat di bidang pendidikan lebih baik.

Salah satu persoalan pendidikan yang sedang dihadapi bangsa kita adalah persoalan mutu pendidikan pada setiap jenjang dan satuan pendidikan. Berbagai usaha telah dilakukan untuk meningkatkan mutu pendidikan nasional, antara lain melalui berbagai pelatihan dan peningkatan kompetensi guru, pengadaan buku dan alat pelajaran, perbaikan sarana dan prasarana pendidikan, dan meningkatkan mutu manajemen sekolah.

Otonomi yang diartikan kewenangan/kemandirian, yaitu kemandirian dalam mengatur dan mengurus dirinya sendiri, dan merdeka/tidak tergantung. Otonomi sekolah adalah kewenangan sekolah untuk mengatur dan mengurus kepentingan warga sekolah menurut prakarsa sendiri berdasarkan aspirasi warga sekolah sesuai dengan peraturan perundang-undangan pendidikan nasional yang berlaku. Kemandirian yang dimaksud didukung oleh sejumlah kemampuan, yaitu kemampuan mengambil keputusan yang terbaik, kemampuan berdemokrasi/menghargai perbedaan pendapat, kemampuan memobilisasi sumberdaya, kemampuan memilih cara pelaksanaan yang terbaik, kemampuan berkomunikasi dengan cara yang efektif, kemampuan memecahkan persoalan-persoalan sekolah, kemampuan adaptif dan antisipatif, kemampuan bersinergi dan berkolaborasi, dan kemampuan memenuhi kebutuhannya sendiri. Pengambilan 
keputusan partisipatif adalah suatu cara untuk mengambil keputusan melalui penciptaan lingkungan yang terbuka dan demokratik, di mana warga sekolah (guru, siswa, karayawan, orangtua siswa, tokoh masyarakat) didorong untuk terlibat secara langsung dalam proses pengambilan keputusan yang dapat berkontribusi terhadap pencapaian tujuan sekolah.

Proses belajar mengajar merupakan kegiatan utama sekolah. Sekolah diberi kebebasan memilih strategi, metode, dan teknik-teknik pembelajaran dan pengajaran yang paling efektif, sesuai dengan karakteristik mata pelajaran, karakteristik siswa, karakteristik guru, dan kondisi nyata sumberdaya yang tersedia di sekolah. Secara umum, strategi/metode/teknik pembelajaran dan pengajaran yang dipilih harus properubahan yaitu yang mampu menumbuhkan dan mengembangkan daya kreasi, inovasi dan eksperimentasi peserta didik untuk menemukan kemungkinan-kemungkinan baru. Pembelajaran dan pengajaran kontekstual, pembelajaran kuantum, pembelajaran kooperatif, adalah contoh-contoh yang dimaksud dengan pembelajaran yang properubahan.

Sekolah diberi kewenangan untuk menyusun rencana pengembangan sekolah (RPS) atau school-based plan sesuai dengan kebutuhannya. Kebutuhan yang dimaksud, misalnya, kebutuhan untuk meningkatkan pemerataan, mutu, relevansi, dan efisiensi sekolah. Oleh karena itu, sekolah harus melakukan analisis kebutuhan pemerataan, mutu, relevansi dan efisiensi sekolah. Berdasarkan hasil analisis kebutuhan tersebut, kemudian sekolah membuat rencana peningkatan pemerataan, mutu, relevansi dan efisiensi sekolah.

Untuk itu, sekolah harus melakukan evaluasi, khususnya evaluasi yang dilakukan secara internal. Evaluasi internal dilakukan oleh warga sekolah untuk memantau proses pelaksanaan dan untuk mengevaluasi hasil program-program yang telah dilaksanakan. Evaluasi semacam ini sering disebut evaluasi diri. Evaluasi diri harus jujur dan transparan agar benar-benar dapat mengungkap informasi yang sebenarnya.

Saat ini telah terjadi desentralisasi sebagian pengelolaan kurikulum dari pemerintah pusat ke sekolah melalui Permendiknas 22/2006, 23/2006, dan 24/2006. Pengelolaan kurikulum yang dimaksud dinamakan kurikulum tingkat satuan pendidikan (KTSP). Pemerintah Pusat hanya menetapkan standar dan sekolah diharapkan mengoperasionalkan standar yang ditetapkan oleh pemerintah pusat. Padahal kondisi sekolah pada umumnya sangat beragam. Dalam kondisi seperti ini, sekolah dipersilakan memilih cara-cara yang paling sesuai dengan kondisi masing-masing. Sekolah dapat mengembangkan (memperdalam, memperkaya, memperkuat, memperluas, mendiversifikasi) kurikulum, namun tidak boleh mengurangi standar isi yang telah tertuang dalam Permendiknas 22/2006. Selanjutnya sekolah berhak mengembangkan KTSP ke dalam silabus, materi pokok pembelajaran, proses pembelajaran, indikator kunci kinerja, sistem penilaian, dan rencana pelaksanaan pembelajaran. 


\section{METODOLOGI PENELITIAN}

Penelitian ini mengambil lokasi pada Madrasah Tsanawiyah Negeri Luwuk Kabupaten Banggai. Alasan penelitian di tempat ini, disamping alasan geografis yang akan memudahkan transportasi dan komunikasi. Di samping itu, pemilihan tempat penelitian ini secara empiris menarik karena aktivitas yang terkait dengan topik dan variabel permasalahan perlu dikaji melalui upaya penelitian.

Penelitian ini menggunakan pendekatan penelitian kuantitatif yang ditinjau dari Kemandirian dalam pengelolaan kurikum dan pembelajaran sedangkan yang dijadikan subyek dan objek penelitian adalaha Kepala Sekolah, Wakil-Wakil Kepala Sekolah, Guru dan Tata Usaha yang ada di Madrasah Tsanawiyah Negeri Luwuk

Menurut Suharsimi Arikunto (dalam Riduwan, 2007:10) bahwa teknik pengumpulan data adalah cara-cara yang digunakan oleh peneliti untuk mengumpulkan data. Untuk memperoleh data mengenai kemandirian sekolah dalam penerapan manajemen berbasis sekolah yang akan dikumpulkan, diolah dan dianalisis, maka peneliti menggunakan beberapa teknik pengumpulan data melalui observasi, Wawancara, Kuesioner

Analisis Data menurut Hasan ( 2006: 29) adalah memperkirakan atau dengan menentukan besarnya pengaruh secara kuantitatif dari suatu (beberapa) kejadian terhadap suatu (beberapa) kejadian lainnya, serta memperkirakan/ meramalkan kejadian lainnya

Dalam penelitian ini menggunakan teknik analisis kuantitatif yang diperoleh melalui pernyataan responden yang terdapat pada data kuesioner, dan selanjutnya untuk pengecekan keakuratan data tersebut dilakukan pula wawancara, observasi serta dokumentasi. Sedangkan dalam mendeskripsikan data yang diperoleh secara kuantitatif digunakan statistik deskriptif, hal ini dilakukan dalam penelitian ini untuk memperoleh hasil informasi yang benar. Selanjutnya dalam pengolahan data terdapat dua langkah yang digunakan, sebagai berikut :

Selanjutnya setelah melakukan seleksi data adalah mengklasifikasikan data berdasarkan indicator yang diteliti, kemudian memberikan bobot skor untuk setiap alternative jawaban dalam pemberian skor digunakan skala Likert yang merupakan salah satu cara untuk menentukan skor. Kriteria penilaian ini digolongkan dalam lima tingkatan dengan penilaian sebagai berikut: Selalu (SL), Sering (SR), Kadang-Kadang (KK), Jarang (JR) dan Tidak Pernah (TP).

Perhitungan terhadap data yang sudah diberikan skor berdasarkan jenis data yang dikumpulkan yaitu data kualitatif yang kemudian diubah menjadi kuantitatif, maka teknik yang digunakan adalah analisis statistik, yaitu dengan menggunakan rumus statistik (prosentase) yang digunakan untuk mendeskripsikan hasil penelitian dengan rumus sebagai berikut: 


$$
\begin{aligned}
\mathrm{P}= & \frac{\mathrm{f}}{\mathrm{N}} \times 100 \% \\
\mathrm{P} & =\text { Prosentase Jawaban } \\
\mathrm{f} & =\text { frekuensi } \\
\mathrm{N} & =\text { Number Of Cases (banyaknya responden) }
\end{aligned}
$$

Pada penelitian ini rumus yang digunakan adalah Weighted Means Score (WMS). Teknik ini digunakan untuk mendapatkan kecenderungan skor yang diberikan oleh responden pada setiap item pertanyaan sesuai dengan kriteria atau tolak ukur yang digunakan.

Menurut Sudjana (2005:67) teknik Weighted Means Score (WMS) adalah untuk menghitung kecenderungan jawaban responden terhadap variable penelitian. Menghitung nilai rata-rata $(\bar{x})$ untuk pada setiap item pertanyaan pada angket, dengan menggunakan rumus Weighted Means Score (WMS) sebagaimana yang dikemukakan oleh Sudjana (2005:67) adalah sebagai berikut :

$$
\bar{X}=\frac{X i}{N}
$$

Keterangan :

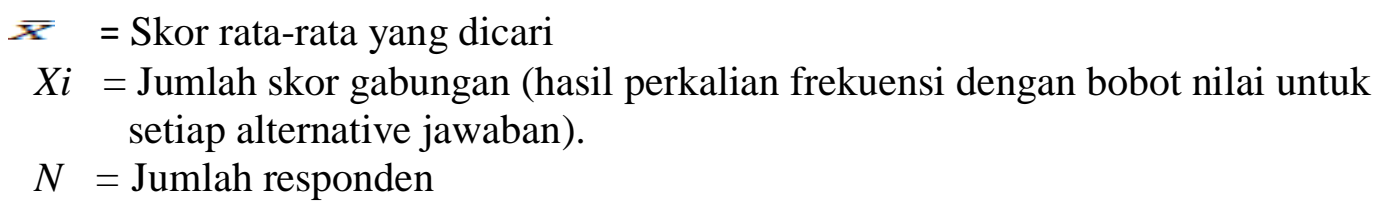

Menentukan variabel yang diukur berdasarkan indicator yang diteliti, maka digunakan skala penilaian oleh Riduwan (2010:15), yaitu sebagai berikut: 86-100\% kriteria sangat tinggi, 71-85\% kriteria tinggi, 51-70 kriteria cukup, 35-50 kriteria rendah dan 0-34 kriteria sangat rendah.

\section{HASIL DAN PEMBAHASAN}

Untuk mencapai tujuan pendidikan di sekolah salah satunya adalah harus dilakukan pengelolaan kurikulum dan pembelajaran Apabila seluruh komponen yang dapat dikelola dengan baik maka tujuan pendidikan yang diharapkan akan tercapai sementara kemandirian dalam pengelolaan kurikumlum dan pembelajaran adalah factor yang menunjang mutu dari pada pendidikan yang dilakukan pada sekolah tersebut. Hasil analisis data terhadap skor tahapan kemandirian dalam pengelolaan kurikulum dan pembelajaran pada Madrasah Tsanawiyah Negeri Luwuk yang dijabarkan dalam 10 item pernyataan sehingga dari pernyataan nomor 1 sampai nomor 10 dilakukan dengan perhitungan teknik Weighted Means Scored (WMS) adalah sebagai berikut. 
Tabel 1. Hasil Perhitungan Persentase Skor Jawaban Responden dalam Tahapan Kemandirian dalam Pengelolaan Kurikulum dan Pembelajaran

\begin{tabular}{|c|c|c|c|c|c|c|c|c|c|c|c|c|c|c|}
\hline \multirow{3}{*}{ Indikator } & \multirow{3}{*}{$\begin{array}{c}\text { No } \\
\text { Item }\end{array}$} & \multicolumn{10}{|c|}{ Bobot Skor } & \multicolumn{2}{|c|}{ Jumlah } & \multirow{3}{*}{$\begin{array}{c}\% \\
\text { skor }\end{array}$} \\
\hline & & \multicolumn{2}{|c|}{5} & \multicolumn{2}{|c|}{4} & \multicolumn{2}{|c|}{3} & \multicolumn{2}{|c|}{2} & \multicolumn{2}{|c|}{1} & & & \\
\hline & & $\mathbf{F}$ & $\mathbf{X}$ & $\mathbf{F}$ & $\mathbf{X}$ & $\mathbf{F}$ & $\mathbf{X}$ & $\mathbf{F}$ & $\mathbf{X}$ & $\mathbf{F}$ & $\mathbf{X}$ & & & \\
\hline \multirow{11}{*}{$\begin{array}{l}\text { Kemandirian } \\
\text { dalam Pengelolaan } \\
\text { Kurikulum dan } \\
\text { Pembelajaran }\end{array}$} & 1 & 32 & 160 & 4 & 16 & 0 & 0 & 1 & 2 & 3 & 3 & 40 & 181 & 90,5 \\
\hline & 2 & 36 & 180 & 4 & 16 & 0 & 0 & 0 & 0 & 0 & 0 & 40 & 196 & 98 \\
\hline & 3 & 33 & 165 & 5 & 20 & 1 & 3 & 1 & 3 & 0 & 0 & 40 & 191 & 95,5 \\
\hline & 4 & 32 & 160 & 6 & 24 & 0 & 0 & 0 & 0 & 2 & 2 & 40 & 186 & 93 \\
\hline & 5 & 26 & 130 & 11 & 44 & 3 & 9 & 0 & 0 & 0 & 0 & 40 & 183 & 91,5 \\
\hline & 6 & 27 & 135 & 6 & 24 & 4 & 12 & 1 & 2 & 2 & 2 & 40 & 175 & 87,5 \\
\hline & 7 & 29 & 145 & 6 & 24 & 3 & 9 & 0 & 0 & 2 & 2 & 40 & 180 & 90 \\
\hline & 8 & 30 & 150 & 6 & 24 & 4 & 12 & 0 & 0 & 0 & 0 & 40 & 186 & 93 \\
\hline & 9 & 28 & 140 & 9 & 36 & 2 & 6 & 0 & 0 & 1 & 1 & 40 & 183 & 91,5 \\
\hline & 10 & 31 & 155 & 7 & 28 & 0 & 0 & 0 & 0 & 2 & 2 & 40 & 185 & 92,5 \\
\hline & & & & & & & & & & & & & & \\
\hline
\end{tabular}

Keterangan:

$\mathrm{F}=$ Frekuensi responden yang menjawab sesuai dengan kategori jawaban

$\mathrm{X}=$ Frekuensi dikalikan dengan bobot nilai kategori jawaban

Sehingga berdasarkan tabel 1 diatas yang disajikan di atas dapat disimpulkan nilai rata-rata persentase skor peroleh pada tahapan kemandirian dalam pengelolaan kurikulum dan pembelajaran pada Madrasah Tsanawiyah Negeri Luwuk, maka diperoleh skor rata-rata 92.25, jika dikonsutasikan pada kriteria penilaian maka disimpulkan kriteria yang diperoleh adalah Sangat Tinggi

Berdasarkan uraian diatas, maka dapat disimpulkan bahwa persentase skor yang tertinggi pada tahapan kemandirian sekolah dalam pengelolaan kurikulum dan pembelajaran di Madrasah Tsanawiyah Negeri Luwuk skor yang diperoleh adalah 92.25\% Hal ini dapat di kategorikan pada tahapan kemandirian dalam pengelolaan kurikulum dan pembelajaran yang dilakukan oleh Madrasah Tsanawiyah Negeri Luwuk sangat mandiri.

Dalam konsep Manajemen Berbasis Sekolah (MBS) kepala sekolah memiliki kewenangan yang memadai untuk menjalankan manajemen sekolahnya. Dalam penelitian Kepala Madrasah Tsanawiyah Negeri Luwuk menjalankan kewenangan untuk menjalankan kebijakan apa saja yang dianggap berpotensi dalam memajukan sekolah, termasuk men-cari dana dan memilih guru yang tepat bagi anak didiknya hal yang dilakukan adalah berupah dalam rangka peningkatan mutu pendidikan.

Secara teoretis, dalam konsep Manajemen Berbasis Sekolah (MBS) maka kewenangan yang dimiliki kepala sekolah bersifat penuh; namun di dalam prakteknya 
kewenangan tersebut seringkali terkurangi oleh kebijakan-kebijakan yang ditentukan oleh pemerintah, baik pemerintah pusat maupun pemerintah daerah setempat. Sebagai contoh yang konkrit, kepala sekolah sesungguhnya mempunyai kewenangan penuh untuk memilih kurikulum yang tepat bagi siswa akan tetapi pemerintah membuat kebijakan mengenai penyeragaman kurikulum (nasional) yang harus dijalankan oleh sekolah selanjutnya sekolah dalam penyelenggaraan Manajemen Berbasis Sekolah bertujuan peningkatan mutu pendidikan melalui pendekatan pemberdayaan sekolah dalam mengelola institusinya.

Manajemen Bebasis Sekolah (MBS) bermaksud mengembalikan sekolah kepada pemiliknya dalam arti yang mengetahui perkembangan sekolah baik di bidang mutu maupun lainya tergantung pada sekolah dan masyarakat partisipannya. Kepala sekolah merupakan orang yang paling tahu tentang prestasi guru-gurunya, kekurangan buku, sarana-prasarana yang menyangkut proses pembelajaran. Untuk itu kepala sekolah dan guru-guru harus dikembangkan kemampuannya dalam melakukan kajian serta analisis agar semakin peka terhadap masalah-masalah yang terjadi di sekolahnya.

Berdasarkan perhitungan WMS, dengan skor yang diperoleh tahapan kemandirian dalam pengelolaan kurikulum dan pembelajaran berada pada kategori sangat tinggi dengan perolehan skor 92,25, dengan skor teringgi pada tahapan kemandirian dalam pengelolaan kurikulum dan pembelajaran pada Madrasah Tsanawiyah Negeri Luwuk berapa pernyataan dalam pengelolaan sekolah menyusun jadwal pembelajaran dengan perolehan masing-masing skor 98, sebagaimana hasil wawancara yang dilakukan oleh peneliti kepada Kepala Madrasah Tsanawiyah Negeri Luwuk memberikan penjelasan bahwa penyusunan jadwal pembelajaran sangat penting karena dari jadwal pembelajaran tersebut akan nampaklah tugas masing-masing guru, hal senada juga disampaikan oleh Wakil Madrasah Tsanawiyah Negeri Luwuk Kurikulum memberikan pernyataan bahwa sekolah melakukan penyusunan jadwal pembelajaran dengan memperhatikan kalender pendidikan yang telah disusun sebelumnya dalam penyusunan jadwal pembelajaran dilakukan pada saat setelah pembagian tugas dilakukan hal ini dimaksudkan agar dalam penyusunan tidak terjadi kesalah pahaman dalam tugas yang telah dibagikan.

Sedangkan untuk skor terkecil adalah sekolah menentukan hari libur dengan skor yang diperoleh adalah 87,5. Sebagaimana pula hasil wawancara yang dilakukan oleh peneliti kepada kepala Madrasah Tsanawiyah Negeri Luwuk dalam wawancara memberikan pernyataan bahwa sekolah menentukan hari libur, sebagaimana yang di sampaikan oleh Kepala Sekolah kepada peneliti bahwa dalam penetuan hari libur tidak terlepas dari kalender pendidikan yang telah disusun. Hal ini sejalan yang disampaikan oleh wakil Kepala Madrasah Tsanawiyah Negeri Luwuk.

Jika dilihat dari ringkasan tahapan kemandirian dalam pengelolaan kurikulum dan pembelajaran pada Madrasah Tsanawiyah Negeri Luwuk yang diberikan jawaban responden tersebut, sekolah menunjukan kemandirian dalam pengelolaan kurikulum dan pembelajaran, misalnya sekolah menyusun kalender pendidikan hal ini dilakukan dalam rangkan menyusun kegiatan yang akan dilaksanakan dalam kurun waktu 1 (satu) tahun 
ajaran, sekolah menyusun jadwal pembelajaran, kegiatan ini dilakukan dalam rangka mengorganisasikan acara pembelajaran yang dilakukan oleh guru, sekolah menyusun jadwal ulangan dan Sekolah menyusun ujian, guru perlu melakukan jadwal ulang dalam rangkah mengukur tingkat pemahaman siswa tentang bahasa yang diajarkan hal ini biasa dilakukan jika jadwal ulangan dan jadwal ujian sudah direncanakan dan batas pelajaran yang dijadikan bahan ulangan dan ujian. Sekolah menyusun kegiatan ekstrakulikuler, agar pembelajaran dilakukan lebih kreatif lagi perlu adanya kegiatan ekstrakulikur, Sekolah menentukan hari libur, libur adalah hari dimana harus berhenti kegiatan belajar mengajar sehingga perlu tetapkan hari liburan dilakukan. Selanjutnya sekolah memberikan kebebasan kepada guru dalam menyusun perencanaan pembelajaran, sekolah memberikan kebebasan kepada guru dalam melaksanakan pembelajaran, sekolah memberikan kebebasan kepada guru dalam melakukan penilaian pembelajaran, tiga hal ini akan menunjang proses belajar mengajar akan berhasil dikarenakan perkembangan siswa yang sangat mengetahui jelas adalah seorang guru, sehingga perlu adanya kebebasan dalam tiga hal tersebut. Dan yang terakhir adalah sekolah melakukan pengawasan pembelajaran, pengawasan yang rutin dilakukan sangat menentukan peningkatan pembelajaran, peran aktif sekolah dalam melakukan supervise dapat pula mengetahui kendala-kendala yang dihadapi oleh guru.

\section{KESIMPULAN}

Dari hasil penelitian yang dilakukan di Madrasah Tsanawiyah Negeri Luwuk menunjukan bahwa kemandirian sekolah dalam penerapan manajemen berbasis sekolah menunjukan bahwa Madrasah Tsanawiyah Negeri Luwuk memiliki Kemandirian dalam pengelolaan kurikulum dan pembelajaran menunjukan pada kriteria sangat tinggi.

\section{DAFTAR PUSTAKA}

Akdon. 2006. Strategic Management For Educational Management. PT Alfabeta. Bandung.

Anonim. 2001. Manajemen Peningkatan Mutu Sekolah: Buku I Konsep Pelaksanaan. Direktorat SLP Dirjen Dikdasmen Depdiknas. Jakarta.

Costa, Vincent. P. 2000. Panduan Pelatihan untuk Pengembangan Sekolah. Depdiknas. Jakarta.

Depag RI. 2001. Perencanaan Pendidikan Menuju Madrasah Mandiri.Balitbang. Jakarta.

Departemen Pendidikan Nasional. 2001. Manajemen Peningkatan Mutu Berbasis Sekolah. Direktorat Pendidikan Menengah Umum. Jakarta.

E. Mulyasa. 2003. Pedoman Manajemen Berbasis Madrasah. Departemen Agama RI: Direktorat Kelembagaan Agama Islam dan Direktorat Madrasah dan Pendidikan Agama Islam.

Fred C. Lunenburg \& Allan C. Ornstein, Education Administration: Concepts and Practices (California: Wadsworth, Inc).

Hadari Nawawi dan M. Martini Hadari. 1995. Kepemimpinan Yang Efektif. Gajah Mada University Press. Yogyakarta.

Mulyasa. 2002. Manajemen Berbasis Sekolah. PT Remaja Rosdakarya. Bandung. 
Masaong, Ansar. 2011. Manajemen Berbasis Sekolah. Sentral Media. Malang.

Nurkolis. 2005. Manajemen Berbasis Sekolah. PT. Grasindo. cet ke 2. Jakarta.

Riduwan. 2007. Metode dan Teknik Menyusun Tesis. Penerbit Alfabeta. Bandung.

Syaiful Sagala. 2007. Manajemen Strategik dalam Peningkatan Mutu Pendidikan.

Penerbit Alfabeta. Bandung.

Sudarwan Danim 2012. Otonomi Manajemen Sekolah. Alfabeta. cet ke 2. Bandung.

Suharsaputra, Uhar. 2010. Administrasi Pendidikan. Refika Aditama. Bandung.

Zainuddin. 2008. Reformasi Pendidikan: Kritik Kurikulum dan Manajemen Berbasis Sekolah. Pustaka Pelajar. cet. I. Yogyakarta.

Pelatihan Manajemen Pendidikan bagi Kepala SMU se- Indonesia di Malang

Bahan Seminar/Dispok Manajemen Kurikulum dan Pembelajaran Berbasis Sekolah tanggal 14-17 Oktober 2012 penyunting : Dr. Mustiningsih, M.Pd

Bahan Seminar/Dispok Kepemimpinan Kepala Sekolah Dasar Berbasis Sekolah tanggal 14-17 Oktober 2012 penyunting : Dr. Mustiningsih, M.Pd

Peraturan Pemerintah No 19 Tahun 2005 tentang Standar Nasional Pendidikan 